\title{
NOX4 Expression in Human Microglia Leads to Constitutive Generation of Reactive Oxygen Species and to Constitutive IL-6 Expression
}

\author{
Bin Li $^{\mathrm{a}}$ Karen Bedard $^{\mathrm{a}}$ Silvia Sorce ${ }^{\mathrm{a}}$ Boris Hinz $^{\mathrm{b}}$ Michel Dubois-Dauphin ${ }^{\mathrm{a}}$ \\ Karl-Heinz Krause ${ }^{\text {a }}$ \\ a Department of Pathology and Immunology, Faculty of Medicine, University of Geneva, Geneva, Switzerland; \\ ${ }^{b}$ Laboratory of Tissue Repair and Regeneration, CIHR Group in Matrix Dynamics, University of Toronto, \\ Toronto, Ont., Canada
}

\section{Key Words}

Human microglia $\cdot$ Reactive oxygen species $\cdot \mathrm{NADPH}$

oxidase $\cdot$ NOX

\begin{abstract}
Reactive oxygen species (ROS) generation by microglia is implicated in neuroinflammation and neurotoxicity, as well as in host defense, cell proliferation and excitatory amino acid release. Recent studies demonstrate that primary microglia preparations not only express the phagocyte NADPH oxidase NOX2, but also the NOX1 and NOX4 isoforms. Here we investigated the relationship between neuroinflammation and NOX isoform expression in the human microglia cell line clone 3 (HMC3). HMC3 cells are typical microglia, as suggested by the constitutive expression of Iba-1 and CD14, and IFN$\gamma$-induced expression of CD11b, CD68 and MHCII. However, the characteristics of NOX isoform expression and ROS generation by HMC3 cells were unexpected. RT-PCR demonstrated abundant expression of NOX4, but almost no NOX2 mRNA. ROS generation was constitutive and appeared predominantly intracellular, as superoxide was detected within intracellular vesicles, while the cell-permeable $\mathrm{H}_{2} \mathrm{O}_{2}$ was found in the extracellular space. ROS generation by HMC3 was efficiently suppressed by siRNA directed against NOX4, but not by control siRNA. NOX4 suppression did not alter ex-
\end{abstract}

pression of the microglia-typical genes MHCII, CD68 and CD11b, nor did it affect the expression of iNOS, VEGF or TGF$\beta$. However, there was a marked decrease in IL-6 mRNA. Taken together, we demonstrate a constitutive NOX4-dependent ROS generation in a microglial cell line which leads to expression of IL- 6 mRNA. The possibility that microglia could switch from tightly regulated NOX2-dependent ROS generation to constitutive NOX4-dependent ROS generation is of interest for the understanding of the role of microglia in maintaining the balance between neuroprotection and neuroinflammatory damage.

Copyright $\odot 2009$ S. Karger AG, Basel

\section{Introduction}

Microglia cells are resident phagocytes of the central nervous system (CNS). They are thought to migrate as myeloid precursor cells into the CNS during fetal development, where they proliferate and differentiate into microglia. Microglia can exist as resting ramified cells, which are thought to correspond to the noninflammatory, resting microglia phenotype. Upon inflammation, ramified microglia can transform into activated, migrating phagocytic cells, also referred to as ameboid form of microglia. Along with these morphological and function-

\section{KARGER}

Fax +4161306 1234 E-Mail karger@karger.ch www.karger.com
Dr. Karl-Heinz Krause

Department of Pathology and Immunology

Faculty of Medicine, University of Geneva, Rue Michel-Servet 1

CH-1211 Geneva (Switzerland)

Tel. +41 22379 4131, Fax +41 22379 4130, E-Mail karl-heinz.krause@unige.ch 
al transformations, these cells undergo changes in their gene expression profile, expression of surface markers and ion channels, and profile of secreted factors [1]. One of the features that microglia share with other monocytederived phagocytes is the ability to produce reactive oxygen species (ROS) through NADPH oxidases. This ROS generation may contribute to the host defense and to the removal of debris, but also to neuroinflammation and neurodegeneration [2-6]. Microglia express the phagocyte NADPH oxidase NOX2 $[7,8]$, and more recently it has been reported that other NOX isoforms, NOX1 and NOX4 [3], are also expressed. NOX1 has been suggested to mediate microglia neurotoxicity [9], while NOX4 has been suggested to be involved in excitatory amino acid release via volume-regulated anion channels [10].

Humans have 7 different NOX isoforms: NOX1NOX5, DUOX1 and DUOX2. While all these isoforms function to generate ROS, they differ importantly in their tissue distribution, their subcellular localization and the mechanism by which they are regulated. Thus, differences in the expression profile of NOX isoforms could potentially lead to important physiological differences. Indeed, the activation of NOX1, NOX2 and NOX3 depends on cytosolic subunits (NOXA1 and NOXO1 for NOX1 and NOX3, p47 $7^{\text {phox }}$ and p6 $7^{\text {phox }}$ for NOX2) and is generally regulated by kinases [11-13], while the activation of NOX5, DUOX1 and DUOX2 involves intramolecular EF hands and regulation through the cytosolic free $\mathrm{Ca}^{2+}[11$, 14]. NOX4 is a unique NADPH oxidase isoform, as there is little evidence for activation of NOX4 and the enzyme might indeed be constitutively active and controlled rather by changes at the mRNA level [15]. Thus, expression of NOX4 in a given cell is likely to lead to constitutive ROS generation and hence to profoundly modify the phenotype of such a cell.

In this study we characterize a human microglia cell line. We demonstrate constitutive ROS generation through NOX4, which leads to constitutive release of IL-6.

\section{Materials and Methods}

\section{Cell Culture}

The human microglia clone 3 cell line (HMC3 [16]), kindly provided by Prof. Marc Tardieu (University of Paris Sud, Paris, France), was cultured in Eagle's minimum essential medium supplemented with $10 \% \mathrm{FBS}, 50 \mathrm{U} / \mathrm{ml}$ penicillin $\mathrm{G}$ sodium and 50 $\mu \mathrm{g} / \mathrm{ml}$ streptomycin sulfate, and incubated in a humidified atmosphere $\left(10 \% \mathrm{CO}_{2}\right)$ at $37^{\circ} \mathrm{C}$. HMC3 cells were activated by culturing in the medium with IFN- $\gamma(10 \mathrm{ng} / \mathrm{ml})$ for $24 \mathrm{~h}$. PLB-985 cells were cultured in RPMI 1640 medium with $10 \%$ FBS, $50 \mathrm{U} / \mathrm{ml}$ penicillin and $50 \mu \mathrm{g} / \mathrm{ml}$ streptomycin. They were differentiated into neutrophil-like cells by dimethylsulphoxide (DMSO; $1.26 \%$ ) 5 days before use. Astrocytes were derived from human embryonic stem cells as described [17].

\section{Immunofluorescence Staining}

Cells seeded on sterilized round cover glass (24 $\mathrm{mm}$ in diameter) were cultured as described above. After mild fixation (PBS/2\% paraformaldehyde), cells were permeabilized (PBS/Triton-X 0.1\%) and nonspecific binding sites were blocked with $3 \%$ sera from the animal species used to generate secondary antibodies. Cells were then incubated at room temperature for $1 \mathrm{~h}$ with primary antibodies against: glial fibrillary acidic protein (GFAP; Chemicon), ionized calcium-binding adapter molecule 1 (IBA1; Wako), CD14 (Santa Cruz), MHCII (NeoMarkers), CD68 (DakoCytomation) and CD11b (Hybridoma Bank). Immunodetection was performed using Alexa 488- or Alexa 555- conjugated secondary antibodies (Molecular Probes; $1 \mathrm{~h}$ at room temperature, 1/1,000), followed by cell nuclei staining with a 4',6-diamidino-2-phenylindole (DAPI; $300 \mathrm{nM}$ ) solution. Negative controls were performed by using the buffer without first antibody (data not shown). Pictures were taken under a fluorescence microscope (Axioskop2 plus; Zeiss).

\section{Reverse Transcription PCR}

Total RNA was isolated by using RNeasy mini kit (Qiagen) according to the manufacturer's instructions. Reverse transcription of $2 \mu \mathrm{g}$ of RNA was performed using the superscript II kit according to the manufacturer's instructions (Invitrogen). PCR was performed using AccuPrime ${ }^{\mathrm{TM}}$ Taq DNA Polymerase (Invitrogen). Amplification of the housekeeping gene GAPDH was used as control. Primers for PCR detection were designed as follows (product length is given in parentheses after the reverse sequence): NOX1 forward primer: 5' TTA ACA GCA CGC TGA TCC TG 3', NOX1 reverse primer: 5' CAC TCC AGT GAG ACC AGC AA 3' (353 bp); NOX2 forward primer: 5' AAA TGG TGG CAT GGA TGA TT 3', NOX2 reverse primer: 5' GGG ATT GGG CAT TCC TTT AT 3' (475 bp); NOX3 forward primer: 5' CCA GGG CAG TAC ATC TTG GT 3', NOX3 reverse primer: 5'CCG TGT TTC CAG GGA GAG TA 3' (432 bp); NOX4 forward primer: 5' AAC CGA ACC AGC TCT CAG AA 3', NOX4 reverse primer: 5' CCC AAA TGT TGC TTT GGT TT 3' (417 bp); NOX5 forward primer: 5' TAC CTC CTC GTG TGG CTT CT 3', NOX5 reverse primer: 5' GCT CAG AGG CAA AGA TCC TG 3' (535 bp); p22 phox forward primer: 5' GTT TGT GTG CCT GCT GGA GT 3', p22 phox reverse primer: 5' TGG GCG GCT GCT TGA TGG T 3' (298 bp); p47 phox forward primer: 5' CCC AGC CAG CAC TAT GTG TA 3', p47 phox reverse primer: 5' CCC AGG TCT TCT CGT AGT CG 3'(453 bp); p67 phox forward primer: 5' CGA GGG AAC CAG CTG ATA GA 3', p67 phox reverse primer: 5'CAT GGG AAC ACT GAG CTT CA 3'(608 bp); GAPDH forward primer: 5' ATC ACT GCC ACC CAG AAG AC 3', and GAPDH reverse primer: 5' ACC TGG TGC TCA GTG TAG CC 3' (302 bp). NOX1 to NOX5 primers were designed and purchased from Invitrogen. The others were from MWG. The temperatures of all primers are in the range of $59.5-60.5^{\circ} \mathrm{C}$ except the p22 forward one $\left(58.19^{\circ} \mathrm{C}\right)$. Annealing temperature was set at $60^{\circ} \mathrm{C}$.

\section{Real-Time PCR}

HMC3 cells were seeded in 24-well-plates, 40,000 cells/well, with routine culture medium over night. Transfection of NOX4 
siRNA oligos was done according to the manufacturer's instructions of HiPerfect Transfection Reagent (Qiagen). Cells were harvested after $24 \mathrm{~h}$ of transfection by trypsinization.

RNA extraction and reverse transcription processes were the same as mentioned in RT-PCR.

Primers used in Q-PCR were designed as follow (temperature is shown in the parentheses at the end of each primer and product length at the end of each reverse primer sequence): hs-IL- 6 forward primer: 5' CTC CAG GAG CCC AGC TAT GA 3' $\left(61.9^{\circ} \mathrm{C}\right)$; hsIL-6 reverse primer: 5' CCCAGGGAGAAGGCAACTG $3^{\prime}$ $\left(62^{\circ} \mathrm{C}\right.$; $\left.66 \mathrm{bp}\right)$; hs-iNOS forward primer: $5^{\prime}$ GCT GCC AAG CTG AAA TTG AAT $3^{\prime}\left(60.8^{\circ} \mathrm{C}\right)$; hs-iNOS reverse primer: $5^{\prime}$ GAT ATC TTC GTG ATA GCG CTT CTG $3^{\prime}\left(60.8^{\circ} \mathrm{C}, 84 \mathrm{bp}\right)$; hsTGFB1 forward primer: $5^{\prime}$ CTG CTG AGG CTC AAG TTA AAA GTG 3' $\left(61.0^{\circ} \mathrm{C}\right)$; hs-TGFB1 reverse primer: 5' TGA GGT ATC GCC AGG AAT TGT 3' $\left(60.9^{\circ} \mathrm{C}, 79 \mathrm{bp}\right)$; hs-VEGF forward primer: $5^{\prime}$ GCC TCC GAA ACC ATG AAC TTT $3^{\prime}\left(61.7^{\circ} \mathrm{C}\right)$; hs-VEGF reverse primer: 5' CTT GGC ATG TTG GAG GTA GAG 3' $\left(58.9^{\circ} \mathrm{C}, 78 \mathrm{bp}\right)$; hs-EEF1A1 forward primer: $5^{\prime}$ AGC AAA AAT GAC CCA CCA ATG $3^{\prime}\left(61.2^{\circ} \mathrm{C}\right)$; and hs-EEF1A1 reverse primer: $5^{\prime}$ GGC CTG GA TGG TTC AGG ATA 3' $\left(66.0^{\circ} \mathrm{C}, 67 \mathrm{bp}\right)$. Human NOX4 primers used in real-time PCR were the same as used in RT-PCR. There are 7 variants of VEGF up to now. The VEGF primers used here were designed from the conserved region of all 7 variants. All primers were purchased from Invitrogen.

cDNA products were diluted to $1 / 10$ for use. SYBR Green was used as the detector. Primer final concentration was $300 \mathrm{nM}$. PCR was performed in an SDS 7900 HT instrument (384 wells; Applied Biosystems) with the following parameters: $50^{\circ} \mathrm{C}$ for $2 \mathrm{~min}, 95^{\circ} \mathrm{C}$ for $10 \mathrm{~min}$ and 40 cycles of $95^{\circ} \mathrm{C}$ for $15 \mathrm{~s}$ to $60^{\circ} \mathrm{C}$ for $1 \mathrm{~min}$.

Raw cycle of threshold values obtained with SDS 2.2 (Applied Biosystems) were imported in Excel and normalization factor calculated using the GeNorm method [18]. Fold change with respect to the reference gene EEF1A1 was used for analysis.

Polymorphonuclear Neutrophil Isolation and Immunoblotting Polymorphonuclear Neutrophil Isolation

Twenty milliliters of blood with $5 \mathrm{ml} 3.8 \%$ sodium citrate was mixed in $12.5 \mathrm{ml}$ 4\% Dextran T 500 (Pharmacia Biotech Ab). The mixture was kept still for $30 \mathrm{~min}$ at room temperature. Red blood cells were removed and an equal amount of D-PBS was added into the supernatant containing polymorphonuclear neutrophils (PMN). The newly formed mixture was centrifuged for $5 \mathrm{~min}$ at $300 \mathrm{~g}$. The supernatant was removed. Cell pellet was resuspended with an equal amount of D-PBS. Cell suspension was added on the surface of $6 \mathrm{ml}$ Ficoll (Ficoll-Paque; Amersham Bioscience) reagent and centrifuged for $15 \mathrm{~min}$ at $450 \mathrm{~g}$. Cell pellet was treated with $5 \mathrm{ml}$ double-distilled water for $40 \mathrm{~s}$ before adding $5 \mathrm{ml}$ $1.8 \% \mathrm{NaCl}$. Cell suspension was centrifuged for $10 \mathrm{~min}$ at $300 \mathrm{~g}$. PMN cells were in the pellet. Supernatant was discarded. Cell pellet was used to extract protein.

\section{Immunoblotting}

HMC3 cell aliquots from the same flask were treated with or without IFN- $\gamma(10 \mathrm{ng} / \mathrm{ml})$ for $24 \mathrm{~h}$. Cells were collected and lysed to extract protein separately. Protein from human PMN was used as the positive control in gp91 ${ }^{\text {phox }}$ detection. BioRad assay was used for protein quantification. Equal amount of protein was loaded for analysis. After transfer, the membrane was blocked $1 \mathrm{~h}$ at room temperature in $\mathrm{PBS} / 0.5 \%$ Tween-20 buffer containing $5 \%$ fat-free milk (blocking buffer). The membrane was incubated at $4^{\circ} \mathrm{C}$ over night with gp91 $91^{\text {phox }}$ antibody (BD Transduction Laboratories; $1 / 1,000$ diluted in blocking buffer). After washing, the membrane was incubated $1 \mathrm{~h}$ at room temperature with horseradish peroxidase-conjugated secondary antibody (1/10,000 in blocking buffer). Unbound secondary antibody was washed off. ECL kit (GE Healthcare) was used to detect the signal.

\section{Measurement of ROS Generation}

Amplex Red Assay

Extracellular hydrogen peroxide was measured by using the Amplex Ultra Red (Molecular Probes) assay as described [19]. HMC3 cells were trypsinized ( $1 \times$ Trypsin-EDTA; Gibco), collected by centrifugation, and washed with PBS to remove residual medium. Differentiated PLB-985 cells (used as positive control) were washed and re-suspended in Hank's balanced salt solution (HBSS). Cells were counted and seeded in 96-well plates at a density of 20,000 cells/well. The Amplex Ultra Red reaction mixture was prepared in HBSS to the final concentrations of $0.05 \mathrm{U} / \mathrm{ml}$ horseradish peroxidase (Amersham) and $25 \mu \mathrm{M}$ Amplex Red. Phorbol myristate acetate (PMA; Sigma-Aldrich) was added to the final concentration of $0.1 \mu \mathrm{l}$, and diphenylene iodonium chloride (DPI; Sigma-Aldrich) at $10 \mu \mathrm{M}$ when needed. Fluorescence with excitation and emission wavelengths of 544 and $590 \mathrm{~nm}$, respectively, was measured at $37^{\circ} \mathrm{C}$ in a FLUOstar OPTIMA fluorescent plate reader (BMG Labtech).

\section{Luminol Assay}

Cells were cultured and plated as described above for Amplex Ultra Red, except that luminol (10 $\mu \mathrm{g} / \mathrm{ml}$; Sigma) replaced Amplex Ultra Red in the mixture. Luminescence measurement was done at $37^{\circ} \mathrm{C}$ with a WALLAC Victor 1420 (Carmet Scientific).

Nitro Blue Tetrazolium Reduction Assay

Cells seeded into 48 well plates at a density of 80,000 cells/well were washed with HBSS and incubated for $2.5 \mathrm{~h}$ in HBSS containing $0.4 \mathrm{mg} / \mathrm{ml}$ nitro blue tetrazolium (NBT; Sigma-Aldrich). After incubation, cells were washed twice with methanol to remove excess NBT and then fixed with methanol. The cells and the blue formazan precipitate were solubilized in $42 \mu$ l of $2 \mathrm{M}$ potassium hydroxide and $49 \mu \mathrm{l}$ of DMSO. Mixtures were transferred into a 96 -well plate and absorption measured at $630 \mathrm{~nm}$ using the WALLAC Victor 1420.

\section{RNA Interference}

The siRNA oligos directed against human NOX4 mRNA were designed and purchased from Qiagen and Invitrogen. Their sequences were designed as follows (their target section on mRNA is shown in the parentheses at the end of each antisense sequence): NOX4 siRNA-a sense oligo: 5' AAA GCA GGA CAU UCA UGG AGA GCC A 3'; NOX4 siRNA-a antisense oligo: 5' UGG CUC UCC AUG AAU GUC CUG GCU UU 3' (303-327); NOX4 siRNA-b sense oligo: 5' GCA UCU GUU CUU AAC CUC A 3'; NOX4 siRNA-b antisense oligo: 5' UGA GGU UAA GAA CAG AUG C 3'; NOX4 siRNA-c sense oligo: 5' CCA GGA GAU UGU UGG AUA A 3'; NOX4 siRNA-c antisense oligo: 5' UUA UCC AAC AAU CUC CUG G 3'; NOX4 siRNA-d sense oligo: 5' CAG UGA AGA CUU UGU UGA ACU GAA U $3^{\prime}$; and NOX4 siRNAd antisense oligo: 5' AUU CAG UUC AAC AAA GUC UUC ACU $G 3^{\prime}$. These oligos had no complementary target sequence in oth- 


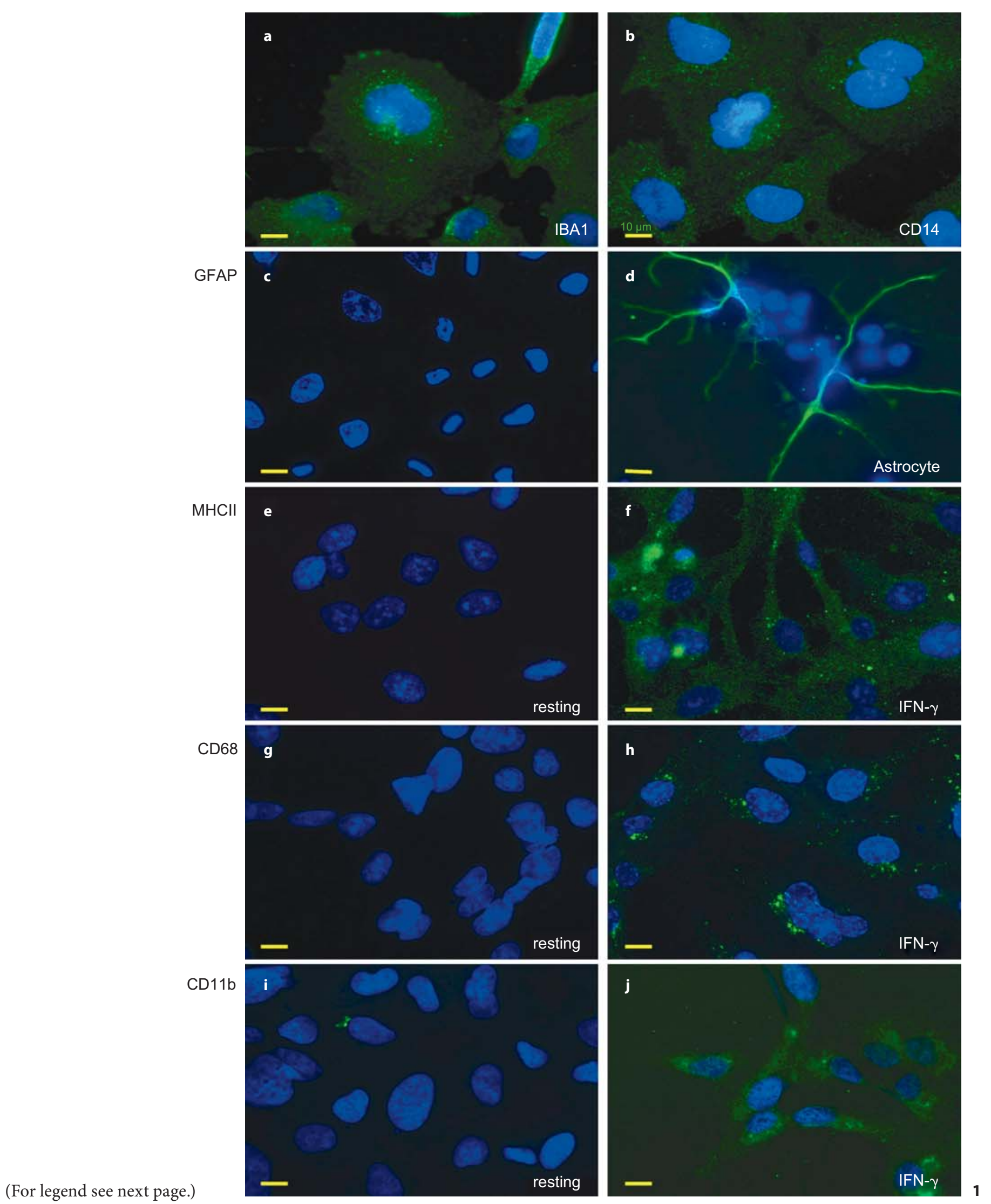


er human NOX isotypes, that is, in NOX1 to NOX5 (data not shown). FITC-conjugated control non-sense siRNA (AllStars Neg. sIRNA AF 488) was purchased from Qiagen.

Cells were either transfected with a mixture of the NOX4 siRNA shown above, or with equivalent amounts of non-sense siRNA. Transfection efficiency (as assessed by using fluoresceinlabeled control siRNA) was $>90 \%$ in all experiments. For the transfection assay with siRNA, 40,000 cells/well were seeded in 24-well plates. Each siRNA oligo was dissolved in double-distilled water and heated at $95^{\circ} \mathrm{C}$ for $5 \mathrm{~min}$ followed by cooling down on ice and was either used immediately or stored at $-20^{\circ} \mathrm{C}$ for later use. siRNA oligos were transfected into the cells by using HiPerFect transfection reagent (as recommended by the manufacturer). All analyses of siRNA-treated cells, that is, ROS measurements, immunofluorescence and real-time PCR, were done $24 \mathrm{~h}$ after siRNA treatment.

\section{Statistical Analysis}

All experiments were done at least on 3 independent occasions. Statistical analysis was processed by using SPSS 13.0 for Windows. In all tests, a $p$ value $<0.05$ was taken as statistically significant. Results are shown in the figures as means \pm standard

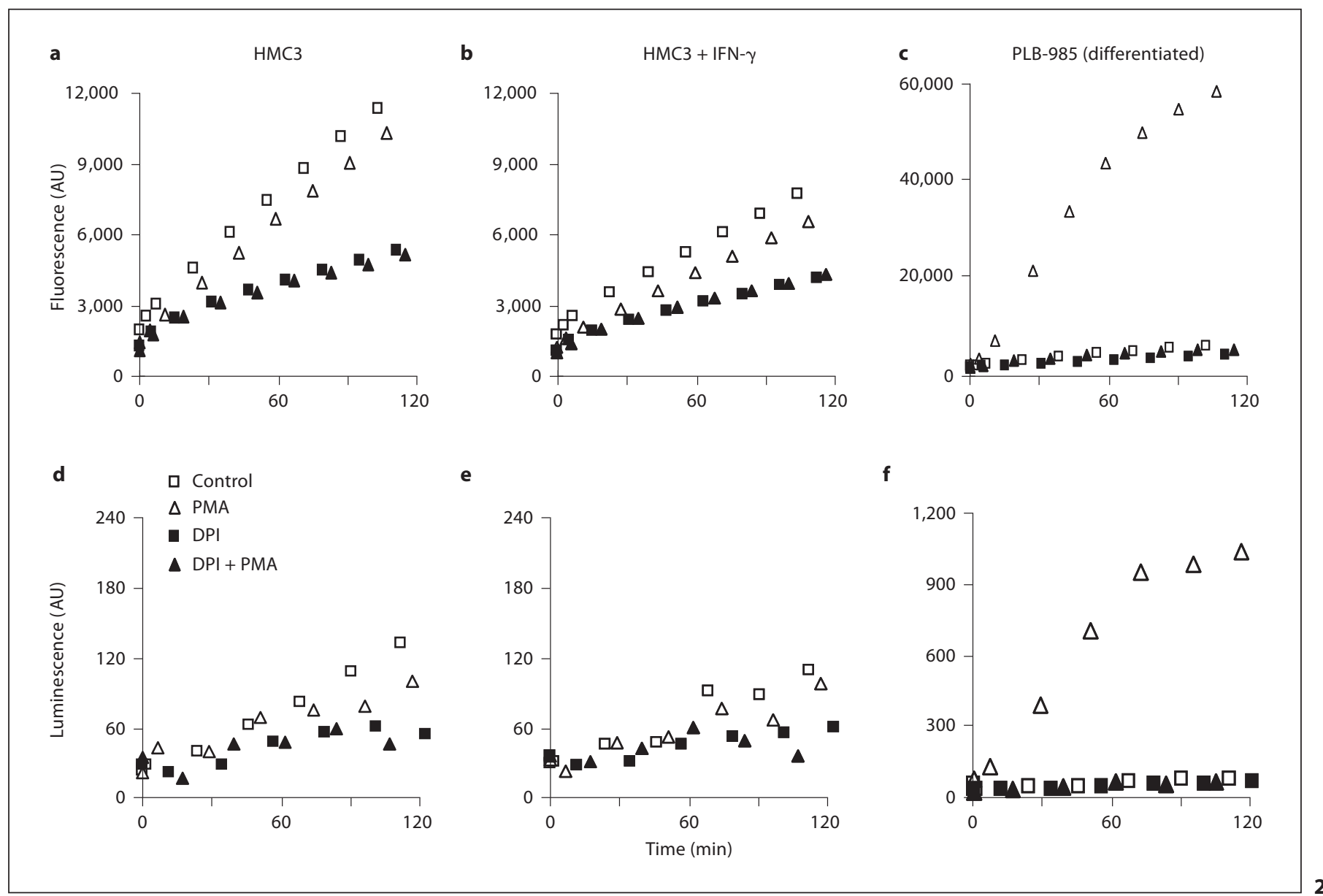

Fig. 1. HMC3 cells express microglia-typical markers and respond to IFN- $\gamma$. HMC3 cells were characterized by immunoflourescence using antibodies directed against markers of resting microglia, astrocytes and activated microglia. For all experiments, cell nuclei were counterstained with DAPI. Resting HMC3 cells were positive for IBA1 (a), weakly positive for CD14 (b), but negative for the astrocyte marker GFAP $(\mathbf{c})$; astrocytes are shown as positive control in panel d. Markers for activated microglia (MHCII, CD68 and CD11b) were absent in resting HMC3 cells (e, g, i); pretreatement with IFN- $\gamma(10 \mathrm{ng} / \mathrm{ml}, 24 \mathrm{~h})$, however, led to expression of these markers $(\mathbf{f}, \mathbf{h}, \mathbf{j})$. Similar results were obtained on at least 3 different occasions. Scale bar $=10 \mu \mathrm{m}$.
Fig. 2. Characterization of ROS generation by HMC3 cells. ROS generation by resting HMC3 cells $(\mathbf{a}, \mathbf{d})$ and IFN- $\boldsymbol{\gamma}$-stimulated HMC3 cells (b, e) was measured using an Amplex Red assay (detects predominantly extracellular hydrogen peroxide) and a luminol-enhanced chemiluminescence assay (detects, in myeloperoxidase-negative cells, predominantly extracellular superoxide). For comparison, ROS generation by DMSO-differentiated PLB cells, that is, NOX2-expressing granulocyte-like cells, was analyzed (c, f). The kinase activator PMA was used to stimulate NOX2-dependent ROS generation. The (nonspecific) NOX inhibitor DPI was used to estimate the background signal. Similar results were obtained in at least 3 independent experiments. 


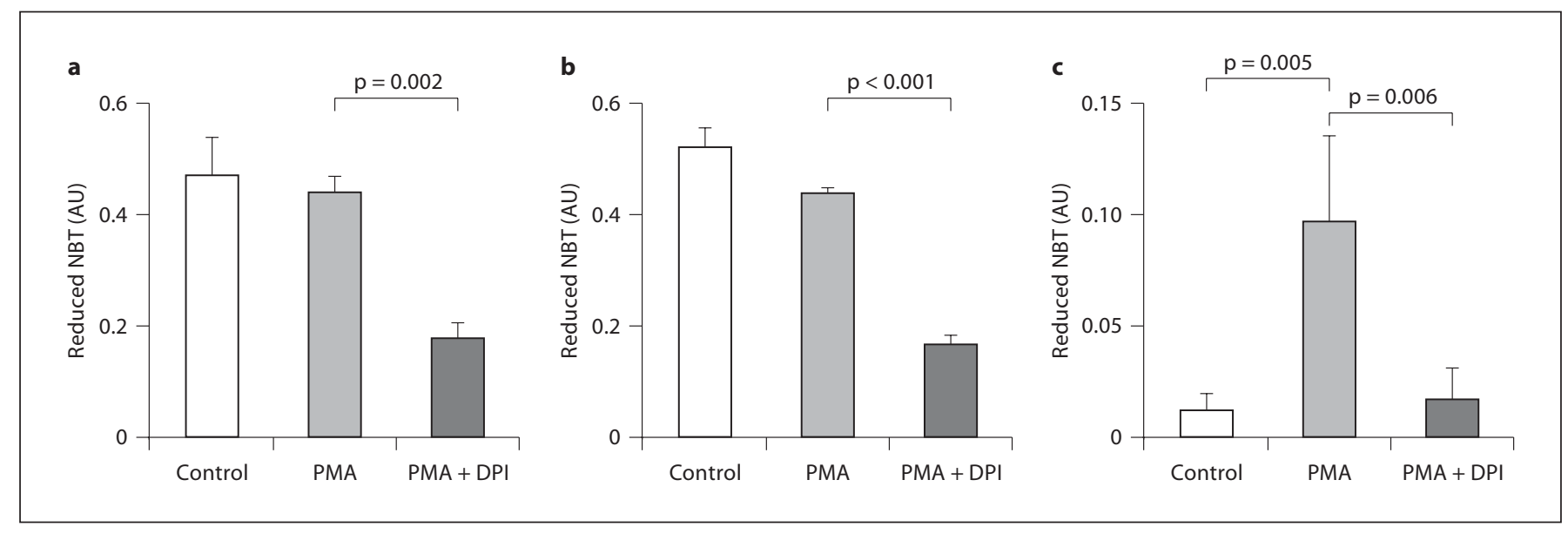

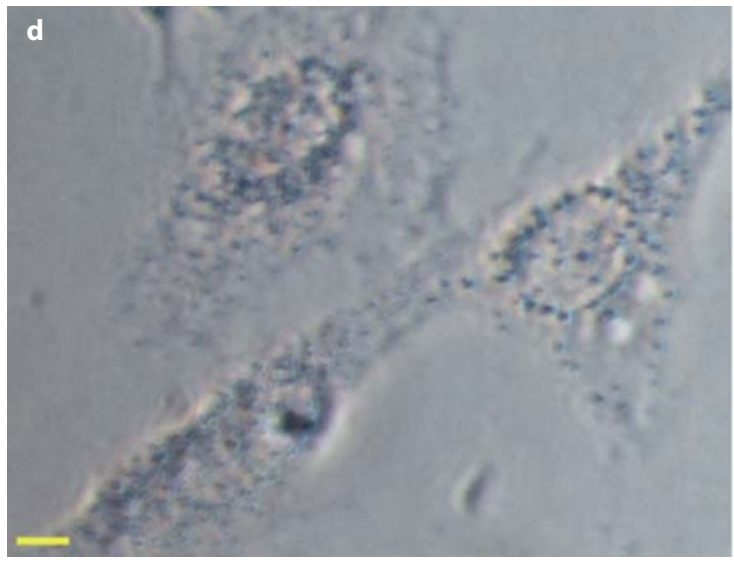

HMC3 NBT

Fig. 3. NBT reduction by HMC3 cells. ROS generation was analyzed by NBT reduction (which detects predominantly intracellular superoxide generation) in resting HMC3 cells (a, d, e), IFN$\gamma$-stimulated HMC3 cells (b) and DMSO-differentiated PLB cells (c). NBT reduction was either analyzed by a quantitative NBT test

error of means. For statistical analysis, one-way ANOVA post hoc multiple comparisons, paired t test, and Wilcoxon's signed-rank test were used, as indicated in the figure legends.

\section{Results}

HMC3 Cells Express Markers of Resting and Activated Microglia

The HMC3 cell line was established through SV40-dependent immortalization of a human fetal brain-derived primary microglia culture [16]. The microglial nature of the cell line was characterized by immunofluorescence (fig. 1). Resting HMC3 cells were strongly positive for the microglia/macrophage marker IBA1 (fig. 1a), positive for the endotoxin receptor CD14 (fig. 1b), but negative for the astrocyte marker GFAP (fig. 1c and d). Markers of activated microglia, namely MHCII (fig. 1e and f), CD68 (fig. 1g and h) and CD11b (fig.1i and j), were negative in resting HMC 3 cells, but upregulated after activation by IFN- $\gamma(10 \mathrm{ng} / \mathrm{ml}, 24 \mathrm{~h})$. Thus, we conclude that HMC3 cells have retained their microglia markers and properties after immortalization and propagation in cell culture.

\section{Characteristics of ROS Generation by HMC3 Cells}

We first investigated $\mathrm{H}_{2} \mathrm{O}_{2}$ release by $\mathrm{HMC} 3$ cells using the Amplex Red assay. Resting HMC 3 cells spontane- 
Fig. 4. Expression of NOX genes in HMC3 cells. NOX gene expression was analyzed by RT-PCR in resting and IFN- $\gamma$-stimulated HMC3 cells. The number of PCR cycles is indicated. a PCR amplification of NOX2 and subunits; human polymorphonuclear cells (hPMN) were used as positive controls, $\mathrm{H}_{2} \mathrm{O}$ as negative control. b PCR amplification of NOX4; HEK293 cells were used as positive controls, $\mathrm{H}_{2} \mathrm{O}$ as negative control. c PCR amplification of NOX1, NOX3 and NOX5; positive controls (human colon as well as NOX3- and NOX5transfected HEK293 cells) are not shown; GAPDH as a housekeeping gene is shown as a control for the quality of the RNA preparation. d NOX2 protein expression was assessed using immunoblotting of HMC3 cells. Human PMN cells were used as positive control. HMC3 cells were treated with/without IFN- $\gamma(10 \mathrm{ng} / \mathrm{ml}, 24 \mathrm{~h})$ before protein extraction. Identical amounts of HMC3 and human PMN material (150 $\mu \mathrm{g}$ protein per sample) were loaded for electrophoresis. Similar results were obtained in 3 independent experiments.

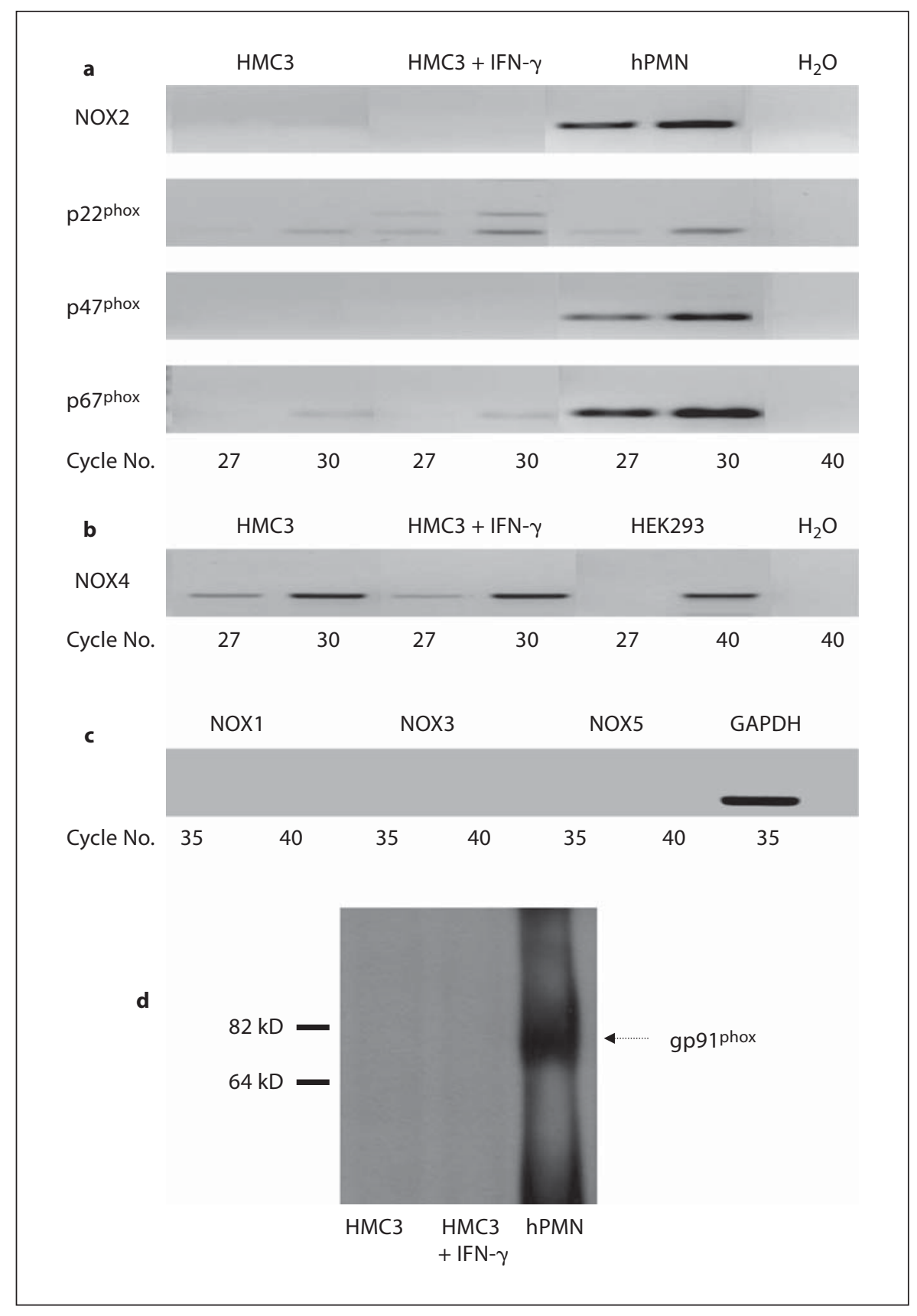

ously released $\mathrm{H}_{2} \mathrm{O}_{2}$ which was blocked by the nonspecific NOX inhibitor, DPI $(10 \mu \mathrm{M})$. However, this signal was not enhanced by stimulation with PMA $(0.1 \mu \mathrm{M})$, which activates NOX2 (fig. 2a). There was also no enhancement of $\mathrm{H}_{2} \mathrm{O}_{2}$ release after IFN- $\gamma$ stimulation of HMC 3 cells and the cells remained unresponsive to PMA (fig. 2b). As a positive control for cells expressing the phagocyte NADPH oxidase NOX2, we used DMSO-dif- ferentiated PLB-985 cells, which have a neutrophil phenotype. As expected, in these cells, spontaneous $\mathrm{H}_{2} \mathrm{O}_{2}$ release was virtually absent, but massively increased after stimulation with PMA (fig. 2c).

$\mathrm{H}_{2} \mathrm{O}_{2}$ is cell permeable, therefore the detection of extracellular $\mathrm{H}_{2} \mathrm{O}_{2}$ does not provide information on the subcellular source of the ROS. However, superoxide is unable to freely cross membranes, therefore, we next in- 


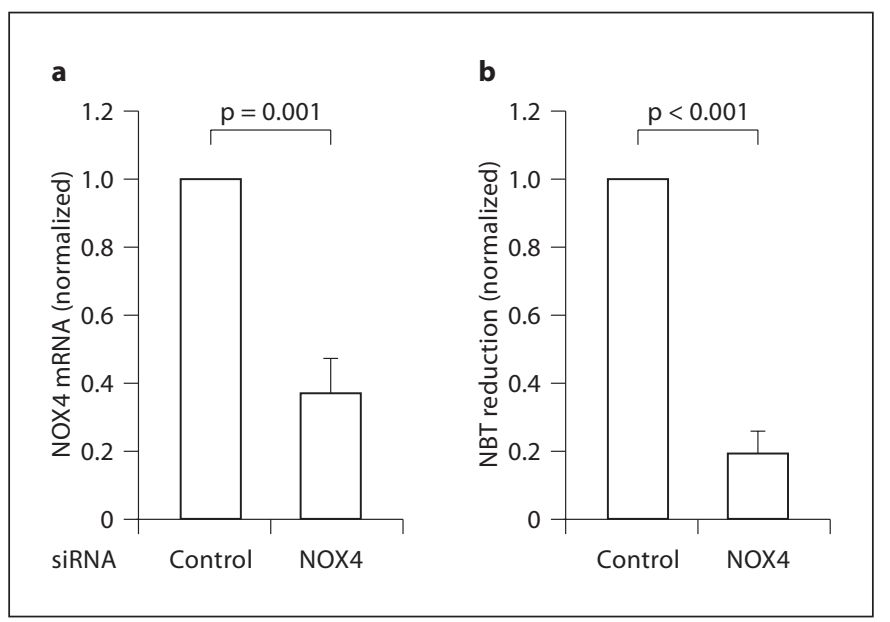

Fig. 5. Impact of NOX4 siRNA on NOX4 mRNA levels and on ROS generation in HMC3 cells. HMC3 cells were transfected with non-sense control siRNA or with NOX4 siRNA and harvested after $24 \mathrm{~h}$. a NOX4 mRNA levels, as detected by real-time PCR. b ROS generation as detected by quantitative NBT analysis. Values were normalized (control $=1$ ). Paired t test was used for statistical analysis.

vestigated extracellular superoxide generation with a luminol-enhanced chemiluminescence assay [15]. Only very low signals were detected with this assay, both in resting and in IFN- $\gamma$-stimulated HMC 3 cells and, as seen for the Amplex Red assay, there was no enhancement of ROS generation by PMA (fig. $2 \mathrm{~d}$ and e). In contrast, a massive signal was observed with PMA-stimulated PLB985 cells (fig. 2c).

We then analyzed intracellular superoxide generation by HMC3 cells using NBT. The soluble and cell-permeable NBT is reduced by superoxide and results in a dark blue formazan precipitate revealing intracellular superoxide generation [15]. Using this quantitative NBT test, we detected a strong signal in HMC3 cells which could be inhibited by DPI. This signal was not enhanced by IFN- $\gamma$ treatment or by PMA stimulation (fig. $3 \mathrm{a}$ and $\mathrm{b}$ ). In contrast, PLB-985 showed only a PMA-induced NBT signal (fig. 3c). Microscopic analysis of NBT-treated HMC3 cells showed DPI-sensitive intracellular formazan precipitations, which were preferentially observed in the perinuclear region (fig. 3d and e).

\section{Expression of NOX Isoforms in HMC3 Cells}

We next analyzed, in resting and IFN- $\gamma$-stimulated HMC3 cells, mRNA expression of different NOX isoforms by using RT-PCR (fig. 4). Under our experimental conditions (27 and 30 cycles), no NOX 2 or $\mathrm{p} 47^{\text {phox }}$ was amplified from mRNA samples from HMC3 cells, while there were weak bands for $\mathrm{p} 22^{\text {phox }}$ and $\mathrm{p} 67^{\text {phox }}$. Note that NOX 2 could be amplified with 40 cycles (not shown). In contrast, a NOX4 band was readily detected in HMC3 cells, already with 27 PCR cycles. mRNA from human neutrophils (NOX2) and HEK293 cells (NOX4; detected only at 40 cycles) served as positive controls. Further, there was no detectable signal for expression of NOX1, NOX3 and NOX 5 mRNA in HMC3 cells, even up to 40 cycles. mRNAs from human colon (NOX1), as well as NOX3- and NOX5-transfected HEK293 cells served as positive controls (data not shown).

As the absence of NOX2 in phagocyte-like microglia was surprising, we verified the PCR results by Western blotting. As shown in figure $4 \mathrm{~d}$, no NOX2 protein was detected in HMC3 cells, while a very strong band was detected in human PMNs.

Taken together, our results revealed a substantial expression of NOX4 mRNA but no expression of NOX1, NOX 3 and NOX 5 mRNA in HMC 3 cells. Although there was possibly a very low-level expression of NOX 2 mRNA, no NOX2 protein could be detected. Finally, the atypical characteristics of spontaneous ROS generation and no activation by PMA suggest that NOX4, rather than NOX2, may be the principal source of ROS in HMC3 cells.

\section{NOX4 siRNA Suppresses ROS Generation in HMC3 \\ Cells}

To investigate whether NOX4 was indeed the source of ROS in HMC3 cells, we performed siRNA experiments. HMC3 cells were transfected with a mixture of siRNA directed against NOX4 (see Materials and Methods) or with the corresponding amounts of non-sense RNA. siRNA directed against NOX4 leads to a decrease of approximately $60 \%$ in NOX $4 \mathrm{mRNA}$, as assessed by realtime RT-PCR (fig. 5a). We next investigated the impact of NOX4 siRNA on ROS generation by HMC3 cells using the quantitative NBT reduction assay. NOX4 siRNA downregulated the NBT signal by approximately $80 \%$ (fig. 5b). Thus, there was a quantitatively comparable downregulation of NOX4 mRNA and ROS generation by NOX4 siRNA.

\section{Impact of NOX4 Knockdown on Protein and Gene Expression in HMC3 Cells}

We next investigated the impact of NOX4 on the expression of proteins and genes in HMC 3 cells. As shown above, there was an upregulation of proteins functionally relevant to activated microglia by IFN- $\gamma$, namely MHCII, 
Fig. 6. Impact of NOX4 siRNA on markers of activated microglia. HMC3 cells were transfected with non-sense control siRNA $(\mathbf{a}, \mathbf{c}, \mathbf{e})$ or with NOX4 siRNA (b, d, f), subsequently treated with IFN- $\gamma$ for $24 \mathrm{~h}$, and analyzed by immunoflourescence using antibodies against MHCII (a, b) CD68 (c, d) and CD11b $(\mathbf{e}, \mathbf{f})$. Nuclei were counterstained with DAPI. Similar results were obtained on at least 3 different occasions. Scale bar $=10 \mu \mathrm{m}$.

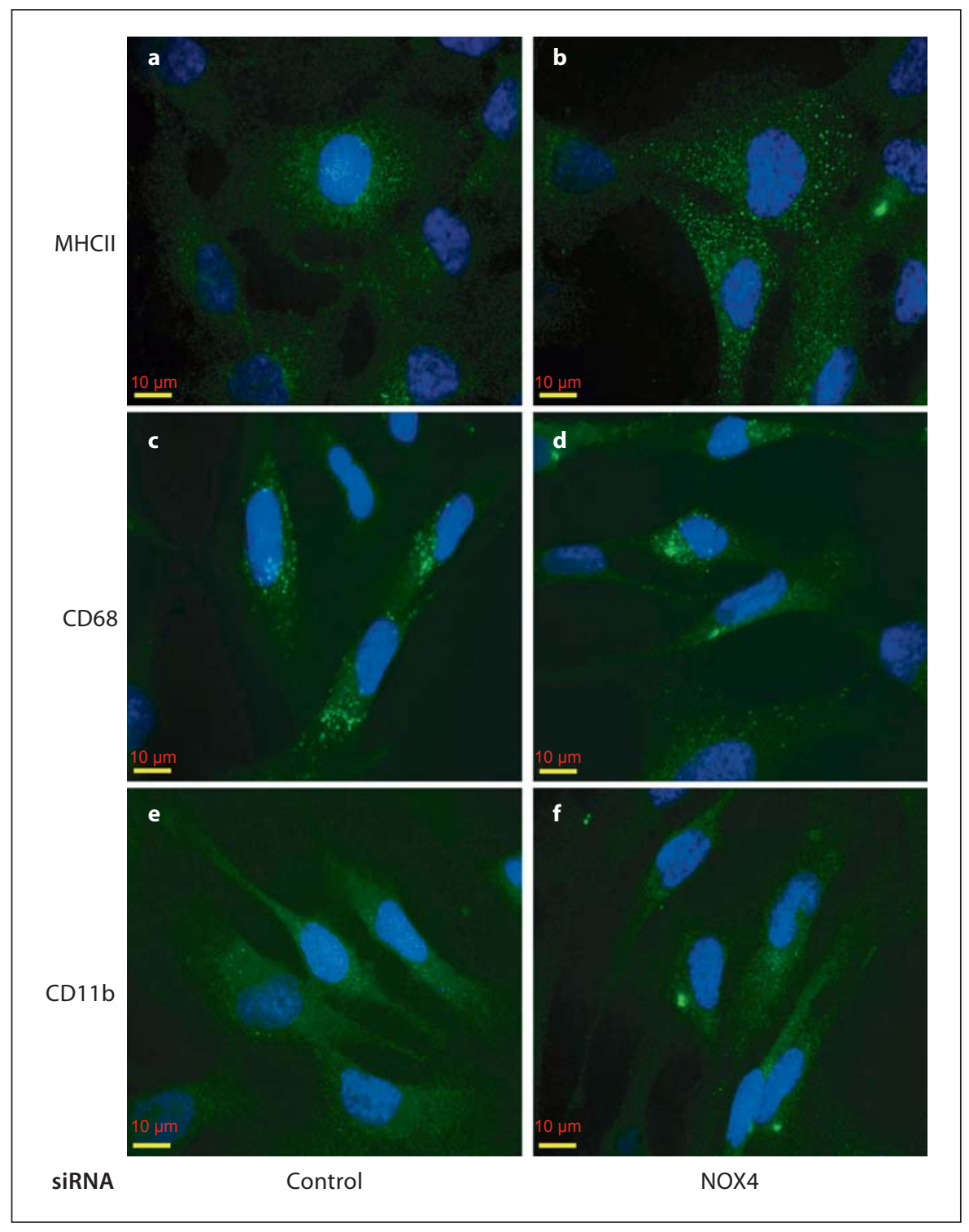

CD68 and CD11b. Treatment of HMC3 cells with NOX4 siRNA did not affect the expression of these proteins, nor the cellular and nuclear morphology (fig. 6). Thus, NOX4dependent ROS generation was not relevant to the IFN$\gamma$-induced upregulation of these proteins. We next investigated the impact of NOX4 siRNA on selected genes whose expression had previously been described to be subject to redox regulation. Downregulation of NOX4 by siRNA did not have a significant impact on mRNA levels of iNOS, VEGF and TGF- $\beta 1 \mathrm{mRNA}$. However, there was a marked downregulation of mRNA of the neuroinflammatory chemokine IL-6 following treatment of HMC3 cells with NOX4 siRNA (fig. 7).

\section{Discussion}

Here we describe a microglia cell line that expresses NOX4, rather than the phagocyte NADPH oxidase NOX2. This altered NOX isoform expression has at least 2 important functional consequences. First, these cells produce ROS in a constitutive manner, independent from external stimuli and second, as a consequence of the former, the cells constitutively express IL-6 mRNA.

Microglia represent between 5 and $20 \%$ of the glial population in the CNS, making them approximately equal in abundance to neurons [1]. Despite this, they remain poorly understood, in part because of the fact that 


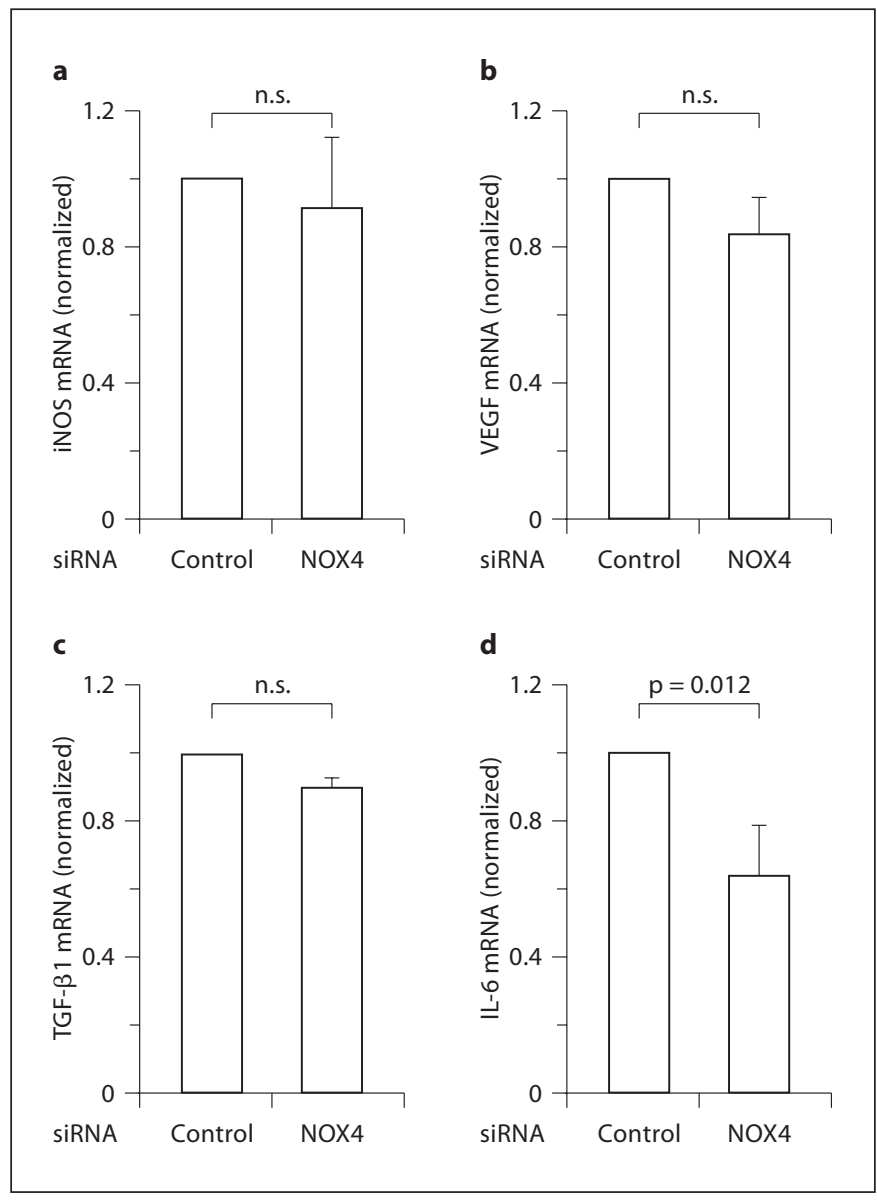

Fig. 7. Impact of NOX4 siRNA on gene expression. HMC3 cells were transfected with non-sense control siRNA or with NOX4 siRNA and harvested after $24 \mathrm{~h}$, and mRNA levels of iNOS (a), VEGF (b), TGF- $\beta 1$, (c) and IL-6 (d) were measured by RT-PCR. Initial ratio values (target gene/housekeeping gene) were normalized (control =1). Wilcoxon's signed-rank test was used for statistical analysis. n.s. $=$ Not significant.

they undergo differentiation and dedifferentiation, existing in many forms with different gene expression profiles, morphological characteristics and functional properties. ROS generation by microglia from humans and other mammalian species is often attributed to NOX2. However, variations in the quantity and properties of the ROS generation have been described. The results from rodent studies suggest that the expression profile of NOX isoforms is likely very complex. Functional studies from p47-deficient mice suggest that this NOX2 subunit is required for microglial ROS generation [7]. However, immunostaining of healthy mouse brains suggested that microglia do not express NOX2 [20]. Similarly, in the brains of healthy rats, immunofluorescence suggested that microglia did not express the cytosolic binding partner of NOX2, p47 ${ }^{\text {phox }}$ [21]. On the other hand, cultures of microglia from mice, rats and humans express NOX2, as well as NOX1 in mice and rats $[9,10]$ and NOX4 rats [10]. While previous studies have found that PMA stimulation of microglia cells leads to an increase in ROS generation, the human cells in the study by $\mathrm{Hu}$ et al. [22] appear to have some baseline ROS generation. Further, the ability of PMA to stimulate ROS generation in porcine microglia changes significantly during the first 4 days in culture [23], and can be modified by treatment with cytokines $[22,23]$. Thus, it appears that, as in other properties of microglia, the profile of NOX isoforms and ROS generation is dependent on the state of the cell, and that NOX2 may not be the only isoform at play, and in fact may not be present at all in the resting state $[9,10]$.

The properties of ROS generation by NOX4 in HMC3 cells are very similar to results that we have previously obtained in HEK293 cells, stably transfected with an inducible NOX4 construct: ROS generation is constitutive and can be detected in the extracellular space mainly as hydrogen peroxide signal, which is probably derived from intracellular superoxide generation as detected by the NBT assay (fig. 2, 3; [15]). As formazan is not thought to diffuse because of its extremely low solubility, this might indicate superoxide generation by intracellular organelles in the region of the endoplasmic reticulum and the nuclear envelope. Note that this corroborates recent suggestions that NOX4 predominantly resides within the endoplasmic reticulum [24]. Although we have not unequivocally identified the intracellular organelle(s) where NOX4-dependent ROS generation occurs, our data, both in HMC3 cells (fig. 3) and in HEK293 cells [15], favor the endoplasmic reticulum. Note that several recent studies using different approaches also report an endoplasmic reticulum localization of NOX4 [24, 25]. Thus, our present working model of NOX4 activity in HMC3 is as follows: NOX4 releases superoxide in the lumen of the endoplasmic reticulum, where it is spontaneously dismutated to hydrogen peroxide. Hydrogen peroxide can freely diffuse through membranes and therefore will diffuse towards the cytoplasm, where it is likely to contribute to redox-dependent signaling [24]. There is generally also some diffusion of hydrogen peroxide to the extracellular space, where it can be detected by Amplex Red. There are also very small amounts of superoxide detected in the extracellular space, which might be either due to a small fraction of NOX4 localized on the cell surface, or due to some diffusion of superoxide through anion channels [11]. 
HMC3 cells are an immortalized cell line. To which extent do our data extend to primary cells and to the in vitro situation? Clearly, expression of NOX4 in primary microglia has been demonstrated [3]. What is not known is whether in vivo there are microglia cells that express exclusively NOX4, as seen in the HMC3 cells, or whether in vivo NOX4 is co-expressed together with NOX2. Better tools, in particular reliable antibodies, will be necessary to distinguish between these possibilities. However, this remaining question does not affect the main message of our study, namely constitutive ROS generation upon expression of NOX4 in microglia.

One of the most interesting features of our study is the fact that the NOX4 expression confers constitutive gene expression of IL- 6 to HMC3 cells. As a member of the neuropoietic cytokine family, IL-6 is involved in the development, differentiation, regeneration, but also degeneration of neurons in the peripheral nervous system and CNS [26]. IL- 6 and its receptor can be expressed by neurons, astrocytes and microglia. The latter 2 cell types are the main source of the cytokine [11]. It is well documented that IL-6 gene expression is redox sensitive, most likely through activation of the NF- $\kappa$ B pathway [27]. However, this activation is generally mediated by NOX 2 and requires cell stimulation, for example by HIV Tat or by mycobacteria $[28,29]$.

An important novelty of our observations lies in the fact that the switch from an activation-dependent NOX enzyme, such as NOX2, to a constitutively active NOX enzyme, such as NOX4, leads to a corresponding constitutive IL-6 gene expression in HMC3. Our data clearly demonstrate that the requirement for stimulus-dependent NOX activation is abolished in NOX4-expressing microglia. This is, to our understanding, the first demonstration that the constitutive activity of the NOX4 enzyme leads to constitutive release of an inflammatory mediator and therefore adds to the understanding of the nature of different NOX isoforms. Importantly, these results have also potential implications for the pathophysiology of diseases of the CNS. IL-6 has been increasingly implicated in a variety of conditions, including Alzheimer's disease [30], loss of hippocampal volume in apparently healthy adults [31] and development of psychosis [32]. Thus, a switch towards NOX4 expression in microglia might contribute to the development of a variety of diseases of the CNS through constitutive ROS generation and constitutive cytokine release.

\section{Acknowledgements}

The authors would like to thank Dr. Marc Tardieu (Paris) for providing the microglia cell line, Christine Deffert and Dr. Jérôme Bonnefont for helpful discussions, François Hermann for help with statistics, and Olivier Plastre for technical help. The work of B.H. was supported by the Gebert Rüf Stiftung and the Swiss National Science Foundation, grants SNF 3100A0-103725 and 3100A0-113733/1.

\section{References}

1 Tambuyzer BR, Ponsaerts P, Nouwen EJ: Microglia: gatekeepers of central nervous system immunology. J Leukoc Biol 2009;5:352-370.

2 Vilhardt F: Microglia: phagocyte and glia cell. Int J Biochem Cell Biol 2005;37:17-21.

3 Sorce S, Krause KH: NOX enzymes in the central nervous system: from signaling to disease. Antioxid Redox Signal 2009.

$\checkmark 4$ Zekry D, Epperson TK, Krause KH: A role for NOX NADPH oxidases in Alzheimer's disease and other types of dementia? IUBMB Life 2003;55:307-313.

5 Wilkinson BL, Landreth GE: The microglial NADPH oxidase complex as a source of oxidative stress in Alzheimer's disease. J Neuroinflammation 2006;3:30.

-6 Qin B, Cartier L, Dubois-Dauphin M, Li B, Serrander L, Krause KH: A key role for the microglial NADPH oxidase in APP-dependent killing of neurons. Neurobiol Aging 2006;27:1577-1587
7 Lavigne MC, Malech HL, Holland SM, Leto TL: Genetic requirement of p47phox for superoxide production by murine microglia. FASEB J 2001;15:285-287.

8 Vilhardt F, Plastre O, Sawada M, Suzuki K Wiznerowicz M, Kiyokawa E, Trono D, Krause KH: The HIV-1 Nef protein and phagocyte NADPH oxidase activation. J Biol Chem 2002;277:42136-42143.

-9 Cheret C, Gervais A, Lelli A, Colin C, Amar L, Ravassard P, Mallet J, Cumano A, Krause $\mathrm{KH}$, Mallat M: Neurotoxic activation of microglia is promoted by a nox1-dependent NADPH oxidase. J Neurosci 2008;28:1203912051.

10 Harrigan TJ, Abdullaev IF, Jourd'heuil D, Mongin AA: Activation of microglia with zymosan promotes excitatory amino acid release via volume-regulated anion channels: the role of NADPH oxidases. J Neurochem 2008;106:2449-2462.
11 Bedard K, Krause KH: The NOX family of ROS-generating NADPH oxidases: physiology and pathophysiology. Physiol Rev 2007; 87:245-313.

12 Gianni D, Bohl B, Courtneidge SA, Bokoch GM: The involvement of the tyrosine kinase $\mathrm{c}$-Src in the regulation of reactive oxygen species generation mediated by NADPH oxidase-1. Mol Biol Cell 2008;19:2984-2994.

13 Kim JS, Diebold BA, Babior BM, Knaus UG, Bokoch GM: Regulation of Nox1 activity via protein kinase A-mediated phosphorylation of NoxA1 and 14-3-3 binding. J Biol Chem 2007;282:34787-34800.

14 Banfi B, Molnár G, Maturana A, Steger K, Hegedûs B, Demaurex N, Krause KH: A $\mathrm{Ca}^{2+}$-activated NADPH oxidase in testis, spleen, and lymph nodes. J Biol Chem 2001; 276:37594-37601 
-15 Serrander L, Cartier L, Bedard K, Banfi B, Lardy B, Plastre O, Sienkiewicz A, Fórró L, Schlegel W, Krause KH: NOX4 activity is determined by mRNA levels and reveals a unique pattern of ROS generation. Biochem J 2007;406:105-114.

-16 Janabi N, Peudenier S, Héron B, Ng KH, Tardieu M: Establishment of human microglial cell lines after transfection of primary cultures of embryonic microglial cells with the SV40 large T antigen. Neurosci Lett 1995; 195:105-108.

17 Suter DM, Preynat-Seauve O, Tirefort D, Feki A, Krause KH: Phenazopyridine induces and synchronizes neuronal differentiation of embryonic stem cells. J Cell Mol Med 2009.

- 18 Vandesompele J, De Preter K, Pattyn F, Poppe B, Van Roy N, De Paepe A, Speleman F.: Accurate normalization of real-time quantitative RT-PCR data by geometric averaging of multiple internal control genes. Genome Biol 2002;3:RESEARCH0034.

19 Bedard K, Attar H, Bonnefont J, Jaquet V Borel C, Plastre O, Stasia MJ, Antonarakis $\mathrm{SE}$, Krause KH: Three common polymorphisms in the CYBA gene form a haplotype associated with decreased ROS generation. Hum Mutat 2009;30:1123-1133.

-20 Serrano F, Kolluri NS, Wientjes FB, Card JP, Klann E: ADPH oxidase immunoreactivity in the mouse brain. Brain Res 2003;988:193198.
1 Kim MJ, Shin KS, Chung YB, Jung KW, Cha CI, Shin DH: Immunohistochemical study of p47Phox and gp91Phox distributions in rat brain. Brain Res 2005;1040:178-186.

$22 \mathrm{Hu}$ S, Chao CC, Khanna KV, Gekker G, Peterson PK, Molitor TW: Cytokine and free radical production by porcine microglia. Clin Immunol Immunopathol 1996;78:9396

23 Tambuyzer BR, Nouwen EJ: Inhibition of microglia multinucleated giant cell formation and induction of differentiation by GMCSF using a porcine in vitro model. Cytokine 2005;31:270-279.

24 Chen K, Kirber MT, Xiao H, Yang Y, Keaney JF Jr: Regulation of ROS signal transduction by NADPH oxidase 4 localization. J Cell Biol 2008;181:1129-1139.

25 Helmcke I, Heumüller S, Tikkanen R, Schröder K, Brandes RP: Identification of structural elements in Nox1 and Nox4 controlling localization and activity. Antioxid Redox Signal 2008.

26 Gadient RA, Otten UH: Interleukin-6 (IL-6) - a molecule with both beneficial and destructive potentials. Prog Neurobiol 1997;52 379-390.
27 Matsusaka T, Fujikawa K, Nishio Y, Mukaida N, Matsushima K, Kishimoto T, Akira S: Transcription factors NF-IL6 and NF- $\kappa$ B synergistically activate transcription of the inflammatory cytokines, interleukin 6 and interleukin 8. Proc Natl Acad Sci USA 1993; 90:10193-10197.

28 Turchan-Cholewo J, Dimayuga VM, Gupta S, Gorospe RM, Keller JN, Bruce-Keller AJ: NADPH oxidase drives cytokine and neurotoxin release from microglia and macrophages in response to HIV-Tat. Antioxid Redox Signal 2009;11:193-204.

29 Yang CS, Lee HM, Lee JY, Kim JA, Lee SJ, Shin DM, Lee YH, Lee DS, El-Benna J, Jo EK: Reactive oxygen species and $\mathrm{p} 47 \mathrm{phox}$ activation are essential for the Mycobacterium tuberculosis-induced pro-inflammatory response in murine microglia. J Neuroinflammation 2007;4:27.

30 Maccioni RB, Rojo LE, Fernández JA, Kuljis RO: The role of neuroimmunomodulation in Alzheimer's disease. Ann NY Acad Sci 2009; 1153:240-246.

-31 Marsland AL, Gianaros PJ, Abramowitch SM, Manuck SB, Hariri AR: Interleukin-6 covaries inversely with hippocampal grey matter volume in middle-aged adults. Biol Psychiatry 2008;64:484-490.

32 Behrens MM, Ali SS, Dugan LL: Interleukin6 mediates the increase in NADPH-oxidase in the ketamine model of schizophrenia. J Neurosci 2008;28:13957-13966. 